\title{
TURISMO E RENDA NA ECONOMIA BRASILEIRA
}

\author{
Márcio Ferreira Coelho*
}

\begin{abstract}
RESUMO: Apresentação de modelos de participação do turismo no Produto Interno Bruto - PIB. Tentativa de conhecer alguns aspectos inacroeconômicos da atividade turística, a partir da matriz insumoproduto da economia turística brasileira. Destaca alguns resultados encontrados nos modelos, fazendo comentários sobre sua importância e validade.
\end{abstract}

UNITERMOS: Turismo: participação no PIB; renda, distribuição; consumo; matriz insumo-produto. Economia: turismo; renda turística.

ABSTRACT: Presentation of participation patterns of the tourism in the gross internal product. Effort to know some macroeconomics features of the touristic activity demonstrating how to distribute the tourist income from the input-output matrix of the brazilian touristic economy. Outstanding of some results from the patterns, considering its importance and validity.

KEYWORDS: Tourism: participation in the gross internal product; income; distribution; consumption; input-output matrix. Economy: tourism; tourist income.

\section{INTRODUÇÃO}

As inovações tecnológicas, principalmente a partir da segunda metade do século $\mathrm{XX}$, propiciaram um crescimento sem precedentes da atividade turística na atualidade. Com um movimento anual de centenas de bilhóes de dólares, o turismo representa um importante segmenio da atividade econômica e até mesmo o setor primordial para a sobrevivência de algumas economias.

No Brasil, apesar de seu caráter incipiente, observa-se um gradativo crescimento da atividade, sendo inegável suas perspectivas de expansão. Contudo, mesmo diante das reais potencialidades do País, o

(*) Mestre em Economia (EPGE/FGV). Bacharel em Ciências Econômicas (FEA/UFF). Analista Econômico da Embratur.

End. para correspondência: EMBRATUR - R. Mariz e Barros, 13 - $7^{\circ}$ andar - 20270

- Rio de Janeiro - RJ - Brasil. 
turismo não tem gerado informações profundas e detalhadas, com razoável nível de embasamento, acerca de alguns aspectos macroeconômicos da atividade.

Muitas foram as tentativas de quantificar os fatos relativos ao turismo com poucos resultados efetivos, restringindo-se os trabalhos, sobretudo, à área acadêmica.

Este texto procura mostrar modelos de estimação da contribuição do turismo ao produto interno bruto, bem como tenta aprofundar o conhecimento sobre a distribuição da renda turística, além de outros fatos macroeconômicos da atividade.

\section{MODELOS DE ESTIMAÇÃO DO PRODUTO TURÍSTICO}

Os modelos de estimação propostos aqui são modos alternativos de mensuração da mesma magnitude, justificando-se suas formulações em virtude das dificuldades encontradas na obtenção de estatísticas padronizadas e completas.

A abordagem básica para a observação da contribuição do turismo ao PIB provém do consumo turístico, uma vez que se deve considerar a enorme dificuldade de definir o que se pode imputar como produção turística, tendo em vista as próprias características da atividade que é muito móvel, possui uma certa imaterialidade nas prestaçōes de serviços, além da dimensão mista quanto às suas definiçōes e elementos que o condicionam. A abordagem através do consumo segue a linha da chamada "escola subjetivista", diametralmente oposta da "escola setorialista" que busca quantificar a atividade turística através da produção (oferta turística). Desta maneira, pode-se considerar que o consumo turístico, observado em sua forma direta e indireta, gera um valor adicionado que pode ser comparado com um valor adicionado global da economia (produto interno bruto). Portanto, tudo o que se deseja é conhecer a participação do valor adicionado pel atividade turística no conjunto do valor adicionado da economia brasileira, num dado período de tempo.

Um primeiro modelo de estimação pode ser descrito como segue:

Participação da Atividade Turística no PIB =

$$
\underline{(\mathrm{CTEB}+\mathrm{CTBB}) \cdot \mathrm{K} \cdot \mathrm{FCI} \cdot \mathrm{R}_{\mathrm{o}}}
$$

onde:

CTEB = consumo turístico dos estrangeiros no Brasil

$\mathrm{CTBB}=$ consumo turístico dos brasileiros no Brasil

$\mathrm{K}=$ multiplicador de produção

$\mathrm{FCI}=$ fator corretor de importaçōes

$\mathrm{R}_{\mathrm{o}}=$ fator de eficiência da economia (relação entre o valor adicionado e o valor bruto da produção)

A utilização do multiplicador de produção $\mathrm{K}$ deve-se à necessidade de observar o consumo turístico em sua forma indireta.

O FCI, componente importado no consumo turístico, funciona como um dreno, ou seja, trata-se do consumo de um bem ou serviço turístico realizado no Brasil produzido no exterior, não devendo, portanto, ser computado.

Já o fator $R_{0}$ surge para que se possa enxergar o valor adicionado pela atividade turística. Na verdade, sendo o valor adicionado em determinada etapa da produção a diferença entre o valor bruto da produção e os consumos intermediários nessa etapa, ao se amortecer lor bruto por um fator $R_{0}$ tem-se o valor adicionado pela atividade turística.

Uma outra abordagem permite observar a participação no PIB utilizando informações diferentes, qual seja:

Participação no PIB $=$ CTEB $\left(1+R_{1} \cdot R_{2}\right)$.

PIB

onde:

$\mathrm{R}_{1}=\frac{\text { pernoites gerados pelo turismo interno }}{\text { pernoites gerados pelo turismo internacional }}$

$\mathrm{R}_{2}=\frac{\text { gasto médio dia dos turistas nacionais }}{\text { gasto médio dia dos turistas estrangeiros }}$

A relação $R_{1}$ mostra a geração de pernoites de turistas bra sileiros por unidade de pernoites de turistas estrangeiros no Brasil

Já a relação $R_{2}$ indica a proporção do gasto médio diário dos turistas domésticos comparado com o mesmo gasto dos turistas estrangeiros no Brasil 
O coeficiente $R_{1} \cdot R_{2}$ exibe o montante de consumo turístico dos brasileiros por unidade de consumo dos estraingeiros no Brasil.

Para a economia brasileira, e baseando-se nas equaçoes acima, encontrou-se uma participação da atividade turística no PIB em torno dos 2,2\% para o ano de 1988.

Outros resultados interessantes, provenientes da própria utiłização das mencionadas equações, revelam que para cada pernoite realizado pelo turista estrangeiro são realizados 17,4 pernoites pelo turista nacional, e, mais ainda, para cada dólar dispendido pelo viajante oriundo do exterior, são gastos US\$2,80 pelo viajante nacional no Brasil.

Outra informação relevante, decorrente da própria natureza do trabalho, refere-se ao montante anual dedicado pelas famílias brasileiras à atividade turística, cerca de $3,2 \%$ do total do consumo de bens e serviços, situando-se dentro da média encontrada em países com renda per capita entre US\$2.000 a US\$5.000. Países cem renda per capita entre US\$10.000 a US\$15.000 dedicam cerca de $10 \%$ a $14 \%$ do total do consumo de bens e serviços para a atividade turística.

\section{RENDA TURÍSTICA E SUA DISTRIBUIÇÃO}

A formulação de uma matriz de insumo-produto da economia turística brasileira possibilitou o conhecimento de alguns aspectos macroeconómicos da atividade, além dos multiplicadores turísticos e outros parâmetros. Não cabe aqui explicitar os aspectos teóricos que estāo por trás dos modelos de insumo-produto, os quais ainda solrem importantes restrições que devem ser consideradas na maioria das aplicaçōes das análises de insumo-produto. Entretanto, acredita-se que as tabelas de insumo-produto podem mostrar conjuntamente a estrutura econômica da atividade turística, sua importância objetiva e suas influências indiretas. O problema da quantificação conjunta não existiria, se o turismo fosse somente a compra e venda de serviços de hotelaria, e não seria ainda muito grande o problema, se também adicionasse à atividade a produção de outros serviços como restaurantes turísticos. Contudo, o turismo influencia diretamente é é influenciado também pelos transportes e pelos serviços de recreação, e indiretamente por outros setores que têm uma clara importância em seu crescimento, como a construção civil, a alimentação, as comunicaçōes etc.
O estudo da forte interdependência que existe entre o turismo e os outros setores econômicos é um dos principais motivos que justificam a construção de tabelas de insumo-produto do turismo. A estimativa da renda turística direta e indireta encontrou um efeito multiplicador de renda para 1988 igual a 1,75, valor este oriundo dos modelos de insumo-produto. De acordo com os resultados dos modelos, a renda turística deve estar distribuída da seguinte maneira: $36,1 \%$ para os salários, $57,3 \%$ para os excedentes (lucros em geral) e o restante para impostos e subsídios.

\section{CONCLUSÕES}

Os modelos de impacto da atividade turística no PIB e de insumo-produto aprofundam o conhecimento dos fatos relativos ao turismo, embora devam ser utilizados com certo cuidado, pelo caráter experimental praticado no caso brasileiro.

Os resultados obtidos, entretanto, parecem não estar longe da realidade do País. A participação do turismo no PIB, em torno dos $2,2 \%$ em 1988 , reflete a pouca importância que a sociedade vem considerando à atividade. É certo que dificilmente o turismo alcance um peso como em determinados países e regiões (na Espanha o peso do turismo no PIB gira em torno dos $10 \%$ ao ano), mas, face às potencialidades e ao desenvolvimento do País, é evidente que existe espaço para uma maior participação.

A fatia dedicada ao turismo pelas famílias brasileiras (cerca de $3 \%$ ao ano do consumo total de bens e serviços), parece estar dentro da média dos países com renda per capita similar ao Brasil.

Os resultados da distribuição da renda turística entre salários e lucros também faz florescer a realidade do País, onde encontram-se níveis bastante elevados de concentração de renda e, especialmente dentro da atividade turística, o pagamento de baixos salários é bem acentuado.

Finalmente, deve-se realçar a importância do turismo interno para o País. No decorrer deste trabalho deparou-se com uma despesa realizada pelo turista brasileiro no Brasil quase que três vezes maior do que a despesa do turista estrangeiro. Esta constatação não deixa de surpreender ao se considerar que, na maior parte das vezes, quando se fala em turismo, automaticamente remete-se o pensamento para o turismo internacional. 


\section{BIBLIOGRAFIA}

1. FIGUEROLA. Manuel. Economia turística. Madrid, Imnasa, 1979.

2. DOMINGO. Teresa et al. Métodos y ejercicios de economia aplicada. Madrid. Pirámide. 1988.

3. FIBGE. Brasil - Matriz de instumo-produto, 1980. FIBGE. maio de 1989. (Textos para discussão. 11. 14).

4. FIBGE. Brasil-Novo - Sistema de comtas nacionais - Metodologia e resultados prosisórios - Ano base 1980. FIBGE. dezembro de 1988. (Textos para discussão, n. 10). 